\title{
CD4/CD8 Ratio Predicts Yellow Fever Vaccine-Induced Antibody Titers in Virologically Suppressed HIV-Infected Patients
}

\author{
Vivian Iida Avelino-Silva, MD, * Karina Takesaki Miyaji, MD,* Augusto Mathias, MHS, $†$ \\ Dayane Alves Costa, MHS, $\uparrow$ Juliana Zanatta de Carvalho Dias, MHS, $\uparrow$ Sheila Barbosa Lima, PhD, $\neq$ \\ Marisol Simoes, MHS, $\neq$ Marcos S. Freire, PhD, $\neq$ Helio H. Caiaffa-Filho, MHS, $\$ \|$ \\ Marisa A. Hong, PhD, † Marta H. Lopes, MD, PhD,* Ana M. Sartori, MD, PhD,* \\ and Esper G. Kallas, MD, PhD*†
}

Background: Yellow fever vaccine (YFV) induces weaker immune responses in HIV-infected individuals. However, little is known about YFV responses among antiretroviral-treated patients and potential immunological predictors of YFV response in this population.

\begin{abstract}
Methods: We enrolled 34 antiretroviral therapy (ART)-treated HIVinfected and 58 HIV-uninfected adults who received a single YFV dose to evaluate antibody levels and predictors of immunity, focusing on $\mathrm{CD}^{+}{ }^{-} \mathrm{T}$-cell count, $\mathrm{CD}^{+} / \mathrm{CD}^{+}$ratio, and Human Pegivirus (GBV-C) viremia. Participants with other immunosuppressive conditions were excluded.
\end{abstract}

Results: Median time since YFV was nonsignificantly shorter in HIV-infected participants than in HIV-uninfected participants (42 and 69 months, respectively, $P=0.16$ ). Mean neutralizing antibody (NAb) titers was lower in HIV-infected participants than HIV-uninfected participants ( 3.3 vs. $\left.3.6 \log _{10} \mathrm{mIU} / \mathrm{mL}, P=0.044\right)$, a difference that remained significant after adjustment for age, sex, and time since vaccination $(P=0.024)$. In HIV-infected participants, lower NAb titers

Received for publication July 3, 2015; accepted August 31, 2015.

From the *Department of Infectious and Parasitic Diseases, University of Sao Paulo Medical School, Sao Paulo, Brazil; †Division of Clinic Immunology and Allergy, University of Sao Paulo Medical School, Sao Paulo, Brazil; †Fundação Oswaldo Cruz Bio-Manguinhos, Rio de Janeiro, Brazil; §Adolfo Lutz Institute, Sao Paulo, Brazil; and \|Laboratories of Medical Investigation LIM-3, University of Sao Paulo Medical School, Sao Paulo, Brazil.

This study has been partially funded by Coordenação de Aperfeiçoamento de Pessoal de Nível Superior (Capes), Ministry of Education, Brazil, and Fundação de Amparo a Pesquisa do Estado de Sao Paulo (Grant Number 2013/05246-8).

Partial results from this study were presented at Conference on Retroviruses and Opportunistic Infection, Seattle, February 23-26, 2015.

The authors have no conflicts of interest to disclose.

V.I.A.-S., K.T.M., A.M.S., M.H.L., and E.G.K. designed and conducted the study. V.I.A.-S. conducted data analysis and manuscript writing. A.M. participated in study design and coordination. D.A.C. and J.Z.d.C.D. conducted GBV-C viremia measurements. S.B.L., M.S., and M.S.F. performed the analysis of YFV NAb titers. H.H.C. and M.A.H. performed HIV viral load assays and $\mathrm{CD} 4^{+}$and $\mathrm{CD} 8^{+} \mathrm{T}$ cells counting. A.M.S. and E.G.K. supervised the study. All authors read and approved the article.

Correspondence to: Vivian I. Avelino-Silva, MD, Av. Dr. Eneas de Carvalho Aguiar, 470, sala 06, Cerqueira Cesar, Sao Paulo, SP, Brazil, Postal code 05403000 (e-mail: viviansilva87@gmail.com).

Copyright (C) 2015 Wolters Kluwer Health, Inc. All rights reserved. were associated with longer time since YFV (rho: $-0.38, P=0.027$ ) and lower $\mathrm{CD}^{+} / \mathrm{CD}^{+}$ratio (rho: $0.42, P=0.014$ ), but not $\mathrm{CD}^{+}{ }^{+}$-cell count $(P=0.52)$. None of these factors were associated with NAb titers in HIV-uninfected participant. GBV-C viremia was not associated with difference in NAb titers overall or among HIV-infected participants.

Conclusions: ART-treated HIV-infected individuals seem to have impaired and/or less durable responses to YFV than HIV-uninfected individuals, which were associated with lower $\mathrm{CD} 4^{+} / \mathrm{CD}^{+}$ratio, but not with $\mathrm{CD}^{+} \mathrm{T}$-cell count. These results supports the notion that low $\mathrm{CD}^{+} / \mathrm{CD}^{+}$ratio, a marker linked to persistent immune activation, is a better indicator of functional immune disturbance than $\mathrm{CD}^{+} \mathrm{T}$-cell count in patients with successful ART.

Key Words: yellow fever vaccine, yellow fever neutralizing antibodies, $\mathrm{HIV}, \mathrm{CD}^{+} / \mathrm{CD}^{+}$ratio, immune activation

(J Acquir Immune Defic Syndr 2016;71:189-195)

\section{INTRODUCTION}

Despite the significant improvements in clinical outcomes for persons living with HIV who receive effective antiretroviral therapy (ART), these patients still experience an increased risk of death and higher prevalence of comorbidities compared with HIV-uninfected persons. ${ }^{1-3}$ Studies have consistently demonstrated that immune activation and inflammation, which decrease but fail to return to normal levels on ART, are strong predictors of residual morbidity and mortality. ${ }^{4-6}$

Vaccine responses are among the clinical outcomes that may be impaired for persons living with HIV. Studies performed in different settings have demonstrated that HIV-infected patients present lower responses to several vaccines, ${ }^{7-9}$ possibly predicted by lower $\mathrm{CD}^{+}{ }^{+}$T-cell count, ${ }^{10,11}$ detectable HIV viral load, ${ }^{12-14}$ and lack of ART use. ${ }^{14,15}$ However, studies on vaccine responses restricted to ART-treated HIV-infected patients are lacking, ${ }^{15}$ and it remains unknown whether ART can completely reverse the detrimental effect of HIV on vaccine responsiveness.

As with other vaccines, yellow fever vaccine (YFV) has impaired efficacy among HIV-infected persons. Reduced duration of seropositivity and reduced rates of seroconversion have been documented and were associated with both detectable HIV viral load at vaccination ${ }^{16-21}$ and lower 
$\mathrm{CD}^{+}{ }^{\mathrm{T}}$-cell counts. ${ }^{20} \mathrm{YFV}$ has unique features that make it particularly suitable to assess immune responses among HIVinfected patients. In healthy individuals, YFV efficacy is very high with long duration of protective antibody levels. ${ }^{22,23}$ Most patients in areas of low endemicity are vaccinated with a single vaccine dose, and exposure to wild yellow fever (YF) is very uncommon, such that measured antibodies most likely result from the previous vaccination.

Recent findings suggest that persistent excessive immune activation may be associated with reduced cellular and humoral responses to $\mathrm{YFV}^{24} \mathrm{~A}$ low $\mathrm{CD} 4^{+} / \mathrm{CD}^{+}$ratio is a simple, clinically available biomarker of immune activation, also correlated with higher risk of mortality among ART-treated HIV-infected patients. ${ }^{25}$ In addition, chronic coinfection with GBV-C, also known as human pegivirus, has been previously associated with reduced markers of innate and adaptive immune activation among HIV-infected patients. ${ }^{26-28}$

In this study, we compared YFV efficacy, as assessed by YFV-specific neutralizing antibody (NAb) titers, between treated $\mathrm{HIV}$-infected patients and HIV-uninfected controls who received a single YFV dose. We examined whether time since vaccination, $\mathrm{CD}^{+} \mathrm{T}$-cell count, $\mathrm{CD}^{+} / \mathrm{CD}^{+}$ratio, and $\mathrm{GBV}-\mathrm{C}$ viremia were associated with YFV NAb titers in this cohort.

\section{METHODS}

\section{Study Population}

Potential participants aged 18 years and above vaccinated with a single dose of the YFV derived from the 17D strain (Bio-Manguinhos; Fiocruz, Rio de Janeiro, Brazil) were selected from vaccine registers and from direct survey in outpatient clinics in a tertiary hospital in Sao Paulo, Brazil. All participants were enrolled between November 2010 and April 2014, and had a registered YFV in a vaccination document. Any time point after vaccination was accepted for inclusion.

HIV-negative persons underwent a rapid HIV test at enrollment. All HIV-infected patients were under ART and had undetectable HIV viral load at enrollment and in at least 2 inspections before enrollment.

For both groups, participants with immunosuppressive conditions other than HIV infection were excluded. These included diabetes, chronic liver, or kidney diseases, any type of non-skin cancer (except resolved Kaposi Sarcoma for HIVinfected participants), and use of oral or parenteral immunosuppressive therapy in the 3 months before enrollment.

\section{Statistical Analysis}

Continuous variables were assessed using a $t$ test or the nonparametrical Wilcoxon rank-sum test when applicable. Categorical variables were evaluated with Pearson $\chi^{2}$ or Fisher exact test. Correlation of log-transformed YFV NAb titers with continuous predictors was performed using Spearman rank correlation test. A linear regression model using robust variance estimation was used to assess the association between HIV status and NAb titers adjusted for age, sex, and time since vaccination. We also used a linear regression model adjusted for age and sex to assess the

190 | www.jaids.com association between GBV-C viremia and $\mathrm{CD}^{+} / \mathrm{CD}^{+}$ratio. For all comparisons, 2-tailed $P$ values less than 0.05 were considered statistically significant. All analyses were performed in Stata Version 13.1 (StataCorp; StataCorp LP, College Station, TX).

\section{Ethical Aspects}

The study was approved by The Ethics Committee at University of Sao Paulo Medical School. All participants signed an informed consent form. HIV tests were performed with pretest and posttest counseling. Confidentiality regarding participant's identifiable information was assured by data storage in locked cabinets and/or secure server, and only deidentified records were available during data management.

\section{Laboratory Methods}

The HIV plasma viral load was determined by reversetranscriptase (RT)-PCR using an Amplicor HIV-1 Monitor Test (Roche Diagnostic Systems, Branchburg, NJ), which has a lower detection limit of 200 copies of HIV per cubic millimeter. $\mathrm{CD}^{+}$and $\mathrm{CD}^{+} \mathrm{T}$ lymphocyte counts were determined by flow cytometry (FACSCalibur, BD Biosciences, CA) using Multitest reagent (BD Biosciences, Franklin Lakes, NJ).

$\mathrm{NAb}$ titers against YF virus were defined by the plaque reduction neutralization test (PRNT) performed at Virologic Technology Laboratory of Bio-Manguinhos (LATEV; FIOCRUZ, Brazil). For the analysis of the protective immune response after vaccination, the PRNT is considered the gold standard, ${ }^{29}$ producing results that are correlated with protection. $^{30,31}$ PRNT was conducted in serial 2-fold dilutions starting at 1:5, in $20 \mu \mathrm{L}$ aliquots of heat-inactivated (at $56^{\circ} \mathrm{C}$ for 30 minutes) serum, in 96-well tissue culture plates as previously described. ${ }^{32}$ A positive serum control for YF NAb (a standard serum prepared in house), properly calibrated by the First International Reference Preparation (NIBSC code: YF) ${ }^{33}$ was included in each run of the PRNT. For neutralization step, each well received a YF viral suspension at concentration approximately 30 plaque forming units per well. After incubation at room temperature for 1 hour, a suspension of Vero cells was added, and the plates were incubated again for 3 hours at $37^{\circ} \mathrm{C}$ in $5 \% \mathrm{CO}_{2}$. The medium was then discarded and the cells overlaid with $100 \mu \mathrm{L}$ per well of medium containing carboxymethylcellulose. After incubation for 6 days at $37^{\circ} \mathrm{C}$ in $5 \% \mathrm{CO}_{2}$, the cell monolayers were fixed with $10 \%$ formalin, stained with $0.04 \%$ crystal violet, and plaques were counted. PRNT titer was defined as the reciprocal of the last serum dilution that reduced the plaque numbers in $50 \%$ relative to the virus control. Linear regression was used to determine $\mathrm{NAb}$ titers. Titers expressed in $\mathrm{mIU} / \mathrm{mL}$ were calculated relative to the antibody content in the international reference serum $(143 \mathrm{IU} / \mathrm{mL})$, which was used to determine the nominal value of the positive serum control $(1115 \mathrm{mIU} / \mathrm{mL})$. Therefore, it was possible to transform NAb titer represented by dilution into $\mathrm{mIU} / \mathrm{mL}$. In this study, results are presented in $\log _{10} \mathrm{mIU} / \mathrm{mL}$. 
GBV-C Viral RNA was extracted from 140uL serum samples using QIAamp Viral RNA Mini Kit (QIAGEN Inc, Valencia, CA), according to the manufacturer's instructions. A $5 \mathrm{uL}$ aliquot of the RNA extracted was used to perform the qRT-PCR with the kit SuperScript III Platinum One-Step Quantitative RT-PCR System with ROX (Life Technologies, Carlsbad, CA) with primers, and a TaqMan probe that amplified and quantified a fragment of $72 \mathrm{pb}$ of the 5 ' nontranslated region $\left(5^{\prime} \mathrm{UTR}\right)$. The reaction was made with $0.5 \mu \mathrm{L}$ of SuperScript III RT/Platinum Taq Mix, $12.5 \mu \mathrm{L}$ of $2 \mathrm{X}$ reaction mix with ROX, $0.75 \mu \mathrm{L}$ of $10 \mu \mathrm{M}$ forward primer RTG1 (5'GTGGTGGATGGGTGATGACA3') (Sigma), $1.25 \mu \mathrm{L}$ of $10 \mu \mathrm{M}$ reverse primer RTG2 (5'GACCCACCTATAGTGGCTACCA3') (Sigma), and $0.4 \mu \mathrm{L}$ of $25 \mu \mathrm{M}$ TaqMan probe [(6'FAM)CCGGGATTTACGACCTACC(TAMRA-6FAM)] (Life Technologies), and the reaction final volume of $25 \mu \mathrm{L}$ was completed with DEPC-treated water. The synthesis of cDNA was performed during the first 15 minutes of reaction at $50^{\circ} \mathrm{C}$. After 2 minutes maintained at $95^{\circ} \mathrm{C}$, the amplification and the quantification were performed during 40 cycles with the following times and temperatures: $95^{\circ} \mathrm{C}, 15$ seconds; $60^{\circ} \mathrm{C}, 30$ seconds. The reading of FAM fluorescence was made during the annealing period at $60^{\circ} \mathrm{C}$.

\section{RESULTS}

Table 1 shows the main demographic and clinic characteristics of the $34 \mathrm{HIV}$-infected participants and 58 HIV-uninfected participants. Median age was 46 years old for HIV-infected participants and 38 years old for controls. The HIV-infected group had a higher percentage of males $(79 \%$ vs. $29 \%$ ). Among the 34 HIV-infected participants, 30 (88\%) reported receiving the YFV after the diagnosis of HIV infection. Median time since YFV was nonsignificantly shorter in HIV-infected participants (41 months) than in HIV-uninfected participants (69 months; $P=0.16$ ). Few participants in either group recalled developing any adverse events after YFV.

TABLE 1. Characteristics of Participants*

\begin{tabular}{|c|c|c|c|}
\hline & $\begin{array}{c}\text { HIV-Infected, } \\
\text { ART-Suppressed, } \\
\text { N = } \mathbf{3 4}\end{array}$ & $\begin{array}{c}\text { HIV-Negative } \\
\text { Controls, } \mathrm{N}=\mathbf{5 8}\end{array}$ & $P$ \\
\hline Age, yrs & $46(41-49)$ & $38(29-48)$ & 0.088 \\
\hline Male gender, no. (\%) & $27(79)$ & $17(29)$ & $<0.001$ \\
\hline Time since YFV, mo & $41(25-119)$ & $69(35-131)$ & 0.156 \\
\hline AE after YFV, no. (\%) & $3(9)$ & $12(21)$ & 0.158 \\
\hline $\begin{array}{l}\mathrm{CD}^{+}{ }^{+} \mathrm{T} \text { count }, \uparrow \\
\text { cells } / \mathrm{mm}^{3}\end{array}$ & $790(603-956)$ & $1120(945-1308)$ & $<0.0001$ \\
\hline $\mathrm{CD}^{+} / \mathrm{CD}^{+}{ }^{+}$ratio $\dagger$ & $0.7(0.5-1.2)$ & $1.8(1.3-2.5)$ & $<0.0001$ \\
\hline GBV-C viremia, $\$$ no. (\%) & $8(42)$ & $15(38)$ & 0.735 \\
\hline $\begin{array}{l}\text { Undetectable HIV viral } \\
\text { load,§ no. }(\%)\end{array}$ & $34(100)$ & - & - \\
\hline \multicolumn{4}{|c|}{$\begin{array}{l}\text { *Continuous variables are presented as median and interquartile ranges. } \\
\text { †Only available on } 49 \text { controls. } \\
\text { †Only available for } 40 \text { controls and } 19 \text { HIV-infected participants. } \\
\text { \$With plasma HIV RNA level }<200 \text { copies per milliliter. } \\
\text { AE, adverse events; ART-suppressed, antiretroviral therapy-suppressed. }\end{array}$} \\
\hline
\end{tabular}

All HIV-infected participants were under stable ART, and a high median $\mathrm{CD} 4^{+} \mathrm{T}$-cell count $(790$ cells per cubic millimeter, interquartile range: 603-956) was observed in this group. However, $\mathrm{CD} 4^{+} \mathrm{T}$-cell count and $\mathrm{CD}^{+} / \mathrm{CD}^{+}$ratio were lower among HIV-infected participants compared with HIV-uninfected controls $(P<0.0001$ for both comparisons). More participants in the HIV-infected group had detectable GBV-C viremia, but this difference did not reach statistical significance $(42 \%$ vs. $38 \%, P=0.74)$.

Mean YF-specific NAb titers were significantly lower in HIV-infected participants $\left(3.3 \log _{10} \mathrm{mUI} / \mathrm{ml}, 95 \% \mathrm{CI}: 3.1\right.$ to 3.5) than HIV-uninfected participants $\left(3.6 \log _{10} \mathrm{mIU} / \mathrm{ml}, 95 \%\right.$ CI: 3.4 to $3.7 ; P=0.044$, Fig. 1 ). This difference remained significant after adjustment for covariates in a multivariate model; mean YF-specific NAb titers among HIV-infected participants was 0.44 times the titers predicted for HIVuninfected subjects adjusted for age, sex, and time since vaccination (95\% CI: 0.22 to $0.90, P=0.024)$. In HIVinfected participants, lower NAb titers were not correlated with $\mathrm{CD}^{+}{ }^{+}$T-cell count (Spearman Rho: $-0.11, P=0.52$ ). However, in this group of patients, lower NAb titers were correlated with longer time since YFV (Spearman Rho: -0.38 , $P=0.027$, Fig. 2) and lower $\mathrm{CD}^{+} / \mathrm{CD}^{+}$ratio (Spearman Rho: $0.42, P=0.014$, Fig. 3). None of these factors were correlated with NAb titers in HIV-uninfected participants.

GBV-C viremia was not associated with difference in $\mathrm{NAb}$ titers overall $(P=0.98)$ or among HIV-infected participants $(P=0.56)$. Furthermore, among HIV-infected participants, GBV-C viremia was not associated with $\mathrm{CD}^{+} /$ $\mathrm{CD}^{+}$ratio in a multivariate model adjusted for age and sex (predicted change in $\mathrm{CD}^{+} / \mathrm{CD}^{+}$ratio $=0.10,95 \% \mathrm{CI}$ : -0.60 to $0.81, P=0.76$ ).

\section{DISCUSSION}

In this study, YF-specific NAb titers were significantly lower among ART-treated HIV-infected patients compared

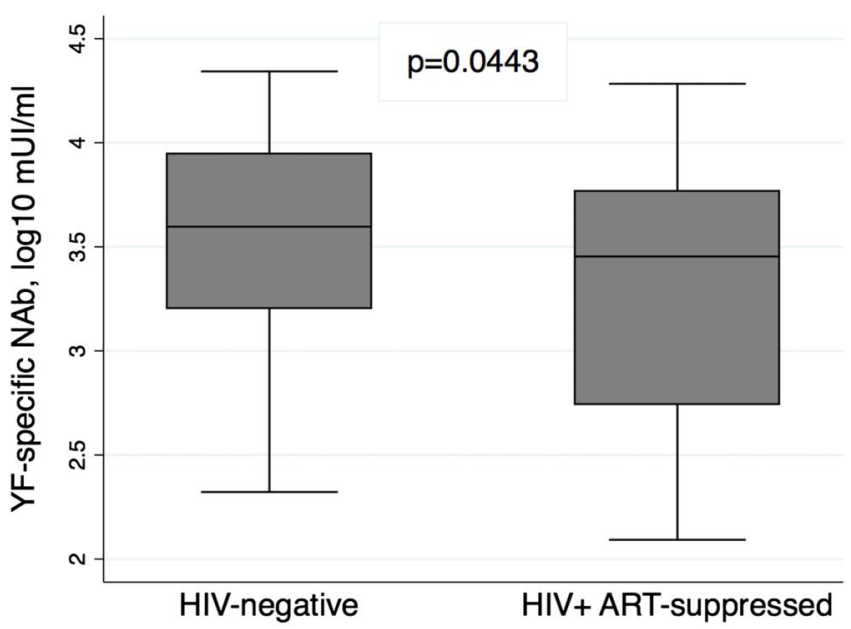

FIGURE 1. NAb titers to YF in HIV-infected participants and HIV-uninfected participants. YF virus-specific NAb titers were $\log _{10}$-transformed. ART, antiretroviral therapy with plasma HIV RNA level $<200$ copies per milliliter.

www.jaids.com | 191 


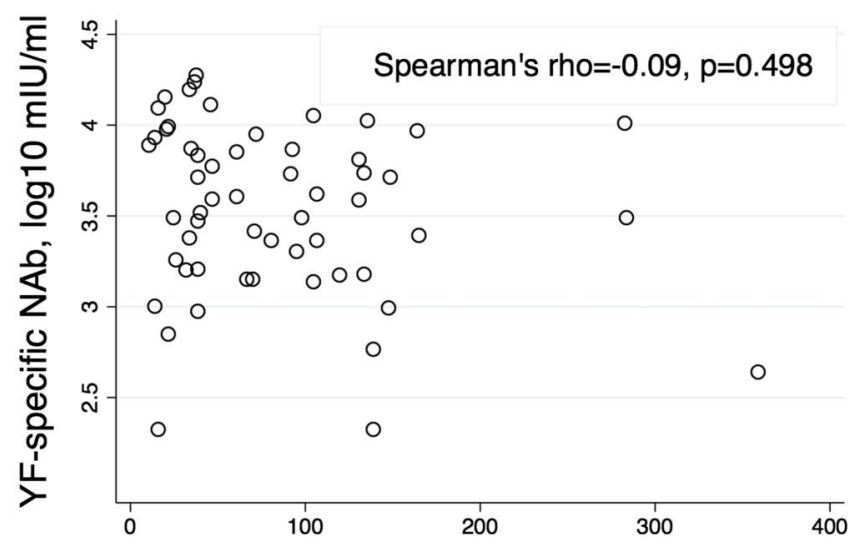

A HIV-negative, Months after YF vaccine

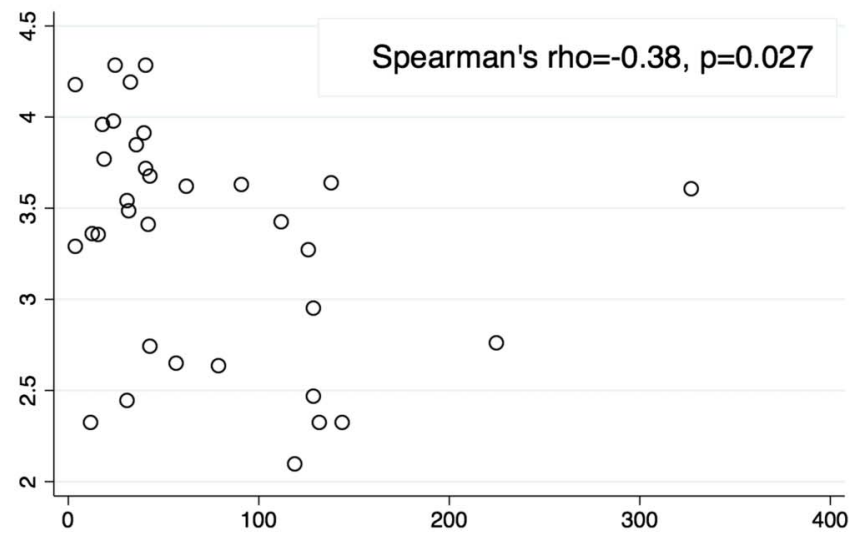

B HIV+ ART-suppressed, Months after YF vaccine

FIGURE 2. Correlation between time since vaccination and YF $\mathrm{NAb}$ titers in HIV-uninfected participants (A) and HIV-infected participants (B).

with HIV-uninfected controls, despite similar time since YFV. Our study also found that among HIV-infected participants, but not among controls, lower NAb titers were correlated with the time elapsed since vaccination and with lower $\mathrm{CD}^{+} / \mathrm{CD}^{+}$ratio. Interestingly, $\mathrm{CD} 4^{+} \mathrm{T}$-cell count was not significantly correlated with YFV NAb titers in our cohort ART-treated HIV-infected patients, and GBV-C viremia had no statistical association with titers of YFV NAb overall or among HIV-infected participants.

Previous studies including both ART-treated and untreated patients with a wider range of $\mathrm{CD}^{+} \mathrm{T}$-cell counts suggested that higher $\mathrm{CD}^{+}{ }^{+} \mathrm{T}$-cell counts were associated with higher levels of YFV antibody response. ${ }^{18,20}$ In our cohort, HIV-infected participants had a remarkably high median $\mathrm{CD}^{+}{ }^{+}$-cell count, consistent with the clinical scenario observed in the present in our setting, where most $\mathrm{HIV}$-infected patients have immediate access to medical care and ART. In this selected sample, YFV response was correlated with $\mathrm{CD}^{+} / \mathrm{CD}^{+}$ratio, but not with $\mathrm{CD} 4^{+} \mathrm{T}$-cell count. It is possible that our findings are not applicable to other low-income or middle-income countries, where HIVinfected patients present with a broader range of $\mathrm{CD}^{+} \mathrm{T}-$

192 | www.jaids.com

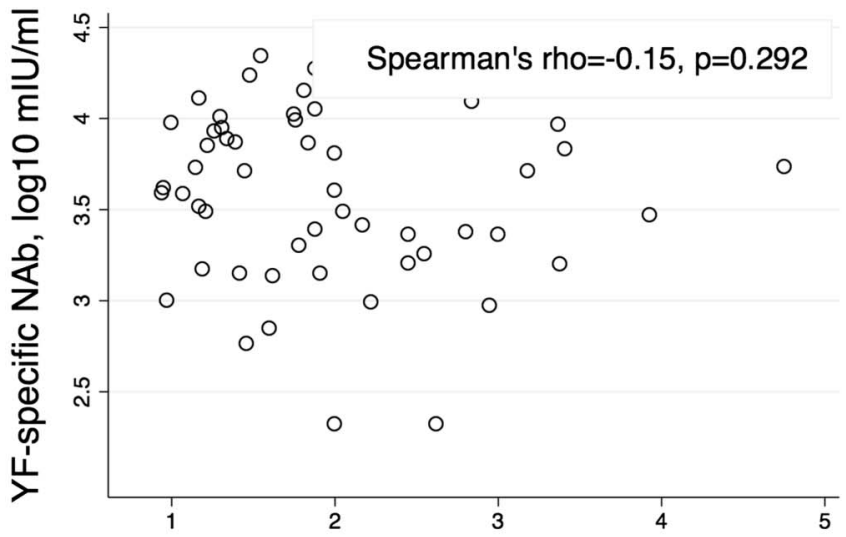

\section{A}

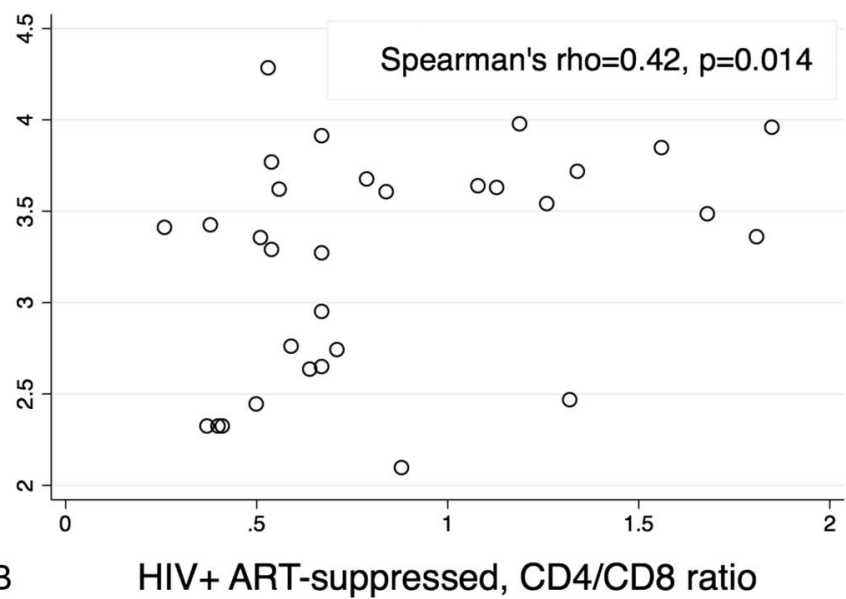

FIGURE 3. Correlation between $\mathrm{CD} 4^{+} / \mathrm{CD} 8^{+}$ratio and YF NAb titers in HIV-uninfected participants (A) and HIV-infected participants (B).

cell count. However, with the recent changes in the recommendations for early antiretroviral initiation, we believe that the range of $\mathrm{CD} 4^{+} \mathrm{T}$-cell count shown in our study will become increasingly representative of HIVinfected patients overall.

Our results are consistent with an extensive literature that suggests treated $\mathrm{HIV}$-infected patients with normal $\mathrm{CD}^{+}$ T-cell counts and undetectable HIV viral load still experience increased morbidity, mortality, and lower responses to vaccines compared with HIV-uninfected subjects. ${ }^{1,15,34}$ In addition, in previous publications, this residual dysfunction was at least partially attributed to a state of persistent immune activation, which improves but fails to normalize after ART initiation and viral suppression. ${ }^{5,35,36}$ Accordingly, impaired responses to vaccines were also correlated with increased immune activation in this population ${ }^{15,37,38}$ and in other chronic inflammatory conditions. ${ }^{39}$ An emerging literature suggests that $\mathrm{CD}^{+} / \mathrm{CD}^{+}$ratio is a better surrogate for functional immune defects than the $\mathrm{CD}^{+} \mathrm{T}$-cell count in treated HIV infection and may be a strong correlate of chronic immune activation predicting detrimental outcomes in this setting. ${ }^{25,40,41}$

Copyright (C) 2015 Wolters Kluwer Health, Inc. All rights reserved. 
Besides $\mathrm{CD}^{+} / \mathrm{CD}^{+}$ratio, other correlates of immune activation may also be associated with impaired vaccine responses. In a recent study of healthy volunteers, Muyanja et al analyzed characteristics of the immune microenvironment before YFV and demonstrated that activation of $\mathrm{CD}^{+} \mathrm{T}$ cells and $\mathrm{B}$ cells, and also activated monocytes before vaccination was correlated with reduced NAb titers after vaccination. Interestingly, African volunteers in this study exhibited less durable T-cell and B-cell YFV responses, which were boosted after a second YFV dose. ${ }^{24}$ In other studies, immune activation was also associated with impaired responses to serogroup $\mathrm{C}$ Neisseria meningitidis vaccine ${ }^{42}$ and influenza vaccine ${ }^{37}$ among HIV-infected patients. Unfortunately, we were unable to investigate the effect of other biomarkers of immune activation on YFV responses in our study. However, in most clinical settings, $\mathrm{CD}^{+} / \mathrm{CD}^{+}$ratio will be the only readily available, easily understood biomarker of immune activation, and may be a useful tool for the prediction of residual morbidity and mortality in treated HIV-infected patients.

We have found an unexpectedly high rate of GBV-C viremia among both HIV-infected participants and HIVuninfected participants, which was not associated with levels of YFV NAb overall or among HIV-infected patients and did not predict $\mathrm{CD}^{+} / \mathrm{CD}^{+}$ratio in the latter group. Chronic infection with GBV-C was consistently associated with improved survival in studies that included HIV-infected patients treated before widespread use of highly active antiretroviral therapy (HAART) or patients in early periods of HAART use. ${ }^{4-46}$ Few studies in the late-HAART period have not been consistent in demonstrating a beneficial effect of GBV-C coinfection, ${ }^{47,48}$ and studies addressing this association among patients with early ART initiation are lacking. Since the hypothesized beneficial effect of GBV-C is to reduce HIV replication and excessive immune activation, ${ }^{27,28,49}$ it is possible that effective and early ART might extinguish any advantage previously conferred by GBV-C coinfection. However, we cannot rule out that our study was underpowered to detect a true difference on YFV NAb titers related to GBV-C viremia.

YFV has been used for several decades as the main strategy for prevention of wild $\mathrm{YF}^{50}$ In healthy individuals, YFV efficacy is elevated, with up to $99 \%$ seroconverting rates, ${ }^{22}$ and the protective response is long lasting, with detectable antibodies up to 35 years after vaccination. ${ }^{23}$ Based on this enduring effect, World Health Organization (WHO) has recently modified its position, suggesting that a single YFV dose is sufficient to confer lifelong protective immunity, and a booster dose is no longer required. ${ }^{51}$ However, as also suggested in the WHO position paper, ${ }^{51}$ our findings indicate that this recommendation may not apply to HIV-infected individuals even in the current era of widespread use of ART. Earlier studies have shown that the duration of YFV response is reduced among HIV-infected persons. We confirmed that this trend persists in our cohort of ART-treated HIV-infected patients, for whom time elapsed after vaccination was inversely correlated with NAb titers. Although median NAb titers among HIV-infected patients in our study were above the previously established seropositivity cutoff point of $2.9 \mathrm{mIU} / \mathrm{ml}^{32}$ the decreasing trend in titers over time suggests that this population may benefit from a booster YFV if exposure to wild YF is likely to occur, as has been suggested previously. ${ }^{52}$ The ideal interval between first vaccination and a booster dose for HIV-infected subjects is at the present unknown. At 5 years or more, 7 of 13 (54\%, 95\% CI: $25 \%$ to $81 \%$ ) HIV-infected participants in our study had protective antibodies. At 10 years, 4 of $8(50 \%, 95 \%$ CI: $16 \%$ to $84 \%)$ $\mathrm{HIV}$-infected participants had protective antibodies. Although not conclusive, this roughly suggests that revaccination may be necessary less than 5 years after first vaccine dose.

Early ART initiation has already been shown to improve immune activation ${ }^{35}$ and hepatitis $B$ virus vaccine response. ${ }^{15}$ We believe that early ART initiation could improve the efficacy of other immunization regimens among HIV-infected individuals, and additional studies addressing how early or late ART initiation would influence vaccine responses could further support the recommendations of immediate ART initiation. It is possible that early ART could even revert the detrimental effect of HIV infection on response to vaccines, but this hypothesis requires additional investigation. However, residual immune activation has been demonstrated despite early ART initiation, ${ }^{35}$ and efficacious, clinically useful interventions to normalize immune activation are still unavailable. At the present, a booster vaccination seems to be the best available recommendation for HIVinfected individuals who are exposed to wild YF.

Our study has several limitations. We did not retrieve the information on ART and HIV suppression status in the HIV-infected group at the time the YFV was received. HIVinfected groups and HIV-uninfected groups were significantly unbalanced by sex, with higher proportion of HIV-infected men $(P<0.001)$. This reflects the prevalence of HIV in our setting, affecting disproportionately men who have sex with men. ${ }^{53}$ Sex may impact vaccine responses in general, ${ }^{54,55}$ and YFV immunogenicity has been shown to be higher among males than females in studies conducted among HIVuninfected participants. ${ }^{56,57}$ Nevertheless, one study in HIVinfected individuals found that females had higher NAb responses than males. ${ }^{18}$ Thus, the effect of sex imbalance in our study is unclear but should not undermine the conclusions of the study because sex was controlled for the in the multivariate analyses. We also had a nonsignificant imbalance of age, with median age of 46 years old in the HIV-infected group and 38 years old in the HIV-uninfected group. Although some studies have suggested that older adults may have impaired response to YFV, the effect of age seems to be more relevant beyond 60 years old, and it is unlikely that the age difference seen in our study had an important impact in results. Furthermore, the difference in NAb titers between groups persisted in the model adjusted for age. Our study also had a limited sample size, which was appropriate for the analysis of NAb titers but was underpowered to analyze the effect of HIV status on seropositivity to YF. Finally, we assessed chronic GBV-C infection with a single measurement of GBV-C viremia and could not discriminate recent unresolved from chronic infections.

In conclusion, the decreased YFV efficacy among HIVinfected patients demonstrated in previous studies seems to persist among HIV-infected individuals on stable ART, who 
seem to have impaired NAb responses to YFV compared with HIV-uninfected individuals with similar time after YFV. Moreover, lower NAb titers were correlated with $\mathrm{CD}^{+} / \mathrm{CD}^{+}$ ratio and time since YFV only among HIV-infected participants. This strengthens the hypotheses that persistent immune activation is a predictor of functional immune defects in ARTtreated, HIV-infected patients, and that strategies to reduce excessive residual inflammation in this population are urgently needed. In addition, it suggests YF-exposed, HIV-infected patients should receive more than a single lifetime YFV dose. Possible strategies for preventing YF in this population include performing periodical measures of NAb titers or delivering a booster dose of YFV. The ideal time point for the booster vaccination remains unknown in this population.

\section{ACKNOWLEDGMENTS}

The authors acknowledge Peter Hunt, Ana Paula Batista, Karina Tiemi Kondo, Karine Milani, Helena Tomiyama, Claudia Tomiyama, Priscila Costa, Joao Miraglia, Zelinda Nakagawa, Claudinir Pereira, Elizete Goya, Solange Cruz, and Maria Candida Dantas and Issler Morais for the support during study execution.

\section{REFERENCES}

1. Bhaskaran K, Hamouda O, Sannes M, et al. Changes in the risk of death after HIV seroconversion compared with mortality in the general population. JAMA. 2008;300:51-59.

2. Antiretroviral Therapy Cohort Collaboration. Life expectancy of individuals on combination antiretroviral therapy in high-income countries: a collaborative analysis of 14 cohort studies. Lancet. 2008; 372:293-299.

3. Schouten J, Wit FW, Stolte IG, et al. Cross-sectional comparison of the prevalence of age-associated comorbidities and their risk factors between HIV-infected and uninfected individuals: the AGEhIV cohort study. Clin Infect Dis. 2014;59(12):1787-97.

4. Hunt PW. HIV and inflammation: mechanisms and consequences. Curr HIV/AIDS Rep. 2012;9:139-147.

5. Hunt PW, Cao HL, Muzoora C, et al. Impact of CD8+ T-cell activation on CD4+ T-cell recovery and mortality in HIV-infected Ugandans initiating antiretroviral therapy. AIDS. 2011;25:2123-2131.

6. Lederman MM, Funderburg NT, Sekaly RP, et al. Residual immune dysregulation syndrome in treated HIV infection. Adv Immunol. 2013; 119:51-83.

7. Rubin LG, Levin MJ, Ljungman P, et al. 2013 IDSA clinical practice guideline for vaccination of the immunocompromised host. Clin Infect Dis. 2014;58:e44-e100

8. Miraglia JL, Abdala E, Hoff PM, et al. Immunogenicity and reactogenicity of 2009 influenza A (H1N1) inactivated monovalent nonadjuvanted vaccine in elderly and immunocompromised patients. PLoS One. 2011;6:e27214.

9. Richardson K, Weinberg A. Reduced immunogenicity of influenza vaccines in HIV-infected compared with uninfected pregnant women is associated with regulatory T cells. AIDS. 2011;25:595-602.

10. Weinberg A, Gona P, Nachman SA, et al. Antibody responses to hepatitis A virus vaccine in HIV-infected children with evidence of immunologic reconstitution while receiving highly active antiretroviral therapy. J Infect Dis. 2006;193:302-311.

11. Abzug MJ, Pelton SI, Song LY, et al. Immunogenicity, safety, and predictors of response after a pneumococcal conjugate and pneumococcal polysaccharide vaccine series in human immunodeficiency virus-infected children receiving highly active antiretroviral therapy. Pediatr Infect Dis J. 2006;25:920-929.

12. Bamford A, Kelleher P, Lyall H, et al. Serological response to 13-valent pneumococcal conjugate vaccine in children and adolescents with perinatally acquired HIV infection. AIDS. 2014;28:2033-2043.
13. Crum-Cianflone NF, Wilkins K, Lee AW, et al. Long-term durability of immune responses after hepatitis A vaccination among HIV-infected adults. $J$ Infect Dis. 2011;203:1815-1823.

14. Lopes VB, Hassing RJ, de Vries-Sluijs TE, et al. Long-term response rates of successful hepatitis B vaccination in HIV-infected patients. Vaccine. 2013;31:1040-1044.

15. Okulicz JF, Le TD, Agan BK, et al. Influence of the timing of antiretroviral therapy on the potential for normalization of immune status in human immunodeficiency virus 1 -infected individuals. JAMA Intern Med. 2015;175:88-99.

16. Goujon C, Tohr M, Feuille V, et al. Good tolerance and efficacy of yellow fever vaccine among subjects carriers of human immunodeficiency virus. Paper presented at: 4th International Conference on Travel Medicine; April 23-27, 1995; Acapulco, Mexico.

17. Sibailly TS, Wiktor SZ, Tsai TF, et al. Poor antibody response to yellow fever vaccination in children infected with human immunodeficiency virus type 1. Pediatr Infect Dis J. 1997;16:1177-1179.

18. Veit $\mathrm{O}$, Niedrig $\mathrm{M}$, Chapuis-Taillard $\mathrm{C}$, et al. Immunogenicity and safety of yellow fever vaccination for $102 \mathrm{HIV}$-infected patients. Clin Infect Dis. 2009;48:659-666.

19. Pistone $\mathrm{T}$, Verdiere $\mathrm{CH}$, Receveur $\mathrm{MC}$, et al. Immunogenicity and tolerability of yellow fever vaccination in 23 French HIV-infected patients. Curr HIV Res. 2010;8:461-466.

20. Sidibe M, Yactayo S, Kalle A, et al. Immunogenicity and safety of yellow fever vaccine among 115 HIV-infected patients after a preventive immunisation campaign in Mali. Trans R Soc Trop Med Hyg. 2012;106:437-444.

21. Pacanowski J, Lacombe K, Campa P, et al. Plasma HIV-RNA is the key determinant of long-term antibody persistence after Yellow fever immunization in a cohort of $364 \mathrm{HIV}$-infected patients. J Acquir Immune Defic Syndr. 2012;59:360-367.

22. Camacho LA, Freire Mda S, Leal Mda L, et al. Immunogenicity of WHO-17D and Brazilian 17DD yellow fever vaccines: a randomized trial. Rev Saude Publica. 2004;38:671-678.

23. Poland JD, Calisher $\mathrm{CH}$, Monath TP, et al. Persistence of neutralizing antibody 30-35 years after immunization with 17D yellow fever vaccine. Bull World Health Organ. 1981:59:895-900.

24. Muyanja E, Ssemaganda A, Ngauv P, et al. Immune activation alters cellular and humoral responses to yellow fever $17 \mathrm{D}$ vaccine. $J$ Clin Invest. 2014;124:3147-3158.

25. Serrano-Villar S, Sainz T, Lee SA, et al. HIV-infected individuals with low $\mathrm{CD} 4 / \mathrm{CD} 8$ ratio despite effective antiretroviral therapy exhibit altered $\mathrm{T}$ cell subsets, heightened CD8+ T cell activation, and increased risk of non-AIDS morbidity and mortality. PLoS Pathog. 2014;10:e1004078.

26. Bhattarai N, Rydze RT, Chivero ET, et al. GB virus C viremia is associated with higher levels of double-negative T cells and lower T-cell activation in HIV-infected individuals receiving antiretroviral therapy. $J$ Infect Dis. 2012;206:1469-1472.

27. Maidana-Giret MT, Silva TM, Sauer MM, et al. GB virus type C infection modulates T-cell activation independently of HIV-1 viral load. AIDS. 2009;23:2277-2287.

28. Stapleton JT, Martinson JA, Klinzman D, et al. GB virus C infection and B-cell, natural killer cell, and monocyte activation markers in HIVinfected individuals. AIDS. 2013;27:1829-1832

29. Niedrig M, Kursteiner O, Herzog C, et al. Evaluation of an indirect immunofluorescence assay for detection of immunoglobulin M (IgM) and $\mathrm{IgG}$ antibodies against yellow fever virus. Clin Vaccine Immunol. 2008; 15:177-181.

30. Niedrig M, Lademann $M$, Emmerich $P$, et al. Assessment of $\operatorname{IgG}$ antibodies against yellow fever virus after vaccination with 17D by different assays: neutralization test, haemagglutination inhibition test, immunofluorescence assay and ELISA. Trop Med Int Health. 1999;4: $867-871$

31. Dobler G, Jelinek T, Frosner G, et al. Cross reactions of patients with acute dengue fever to tick-borne encephalitis [in German]. Wien Med Wochenschr. 1997;147:463-464.

32. Simoes M, Camacho LA, Yamamura AM, et al. Evaluation of accuracy and reliability of the plaque reduction neutralization test (micro-PRNT) in detection of yellow fever virus antibodies. Biologicals. 2012;40:399-404.

33. Control. NIfBSa. WHO Reference Reagent. The 1st International Reference Preparation for Anti-Yellow Fever Serum Monkey NIBSC Code: YF. 2008. Available from: http://www.nibsc.ac.uk/documents/ifu/ YF.pdf. Accessed March 15, 2011.

Copyright (C) 2015 Wolters Kluwer Health, Inc. All rights reserved.

194 | www.jaids.com 
34. Klatt NR, Chomont N, Douek DC, et al. Immune activation and HIV persistence: implications for curative approaches to HIV infection. Immunol Rev. 2013;254:326-342.

35. Jain V, Hartogensis W, Bacchetti P, et al. Antiretroviral therapy initiated within 6 months of HIV infection is associated with lower Tcell activation and smaller HIV reservoir size. J Infect Dis. 2013;208: 1202-1211.

36. Hunt PW, Martin JN, Sinclair E, et al. T cell activation is associated with lower $\mathrm{CD} 4+\mathrm{T}$ cell gains in human immunodeficiency virus-infected patients with sustained viral suppression during antiretroviral therapy. J Infect Dis. 2003;187:1534-1543.

37. Parmigiani A, Alcaide ML, Freguja R, et al. Impaired antibody response to influenza vaccine in HIV-infected and uninfected aging women is associated with immune activation and inflammation. PLoS One. 2013;8: e79816.

38. Boyer JRL, Frank I, Teba P. Chronic inflammation in HIV-1 infected individuals reduces t-cell responsiveness to vaccines. Paper presented at: Conference on Retroviruses and Opportunistic Diseases; February 23-26, 2015; Seattle, WA.

39. Chen S, Akbar SM, Miyake T, et al. Diminished immune response to vaccinations in obesity: role of myeloid-derived suppressor and other myeloid cells. Obes Res Clin Pract. 2015;9:35-44.

40. Vahidnia F, Petersen M, Stapleton JT, et al. Acquisition of GB virus type $\mathrm{C}$ and lower mortality in patients with advanced HIV disease. Clin Infect Dis. 2012;55:1012-1019.

41. Mussini CLP, Cozzi-Lepri A, Lapadula G, et al. CD4/CD8 ratio normalisation and non-AIDS related events in individuals with HIV who achieve viral load suppression with antiretroviral therapy: an observational cohort study. Lancet HIV. 2015;2:e98-e106.

42. Milagres LG, Costa PR, Santos BA, et al. CD4+ T-cell activation impairs serogroup C Neisseria meningitis vaccine response in HIV-infected children. AIDS. 2013;13:2697-2705.

43. Heringlake S, Ockenga J, Tillmann HL, et al. GB virus $\mathrm{C} /$ hepatitis $\mathrm{G}$ virus infection: a favorable prognostic factor in human immunodeficiency virus-infected patients? J Infect Dis. 1998;177:1723-1726.

44. Lefrere JJ, Roudot-Thoraval F, Morand-Joubert L, et al. Carriage of GB virus $\mathrm{C} /$ hepatitis $\mathrm{G}$ virus $\mathrm{RNA}$ is associated with a slower immunologic, virologic, and clinical progression of human immunodeficiency virus disease in coinfected persons. J Infec Dis. 1999;179:783-789.

45. Tillmann HL, Heiken H, Knapik-Botor A, et al. Infection with GB virus $\mathrm{C}$ and reduced mortality among HIV-infected patients. $N$ Engl $J$ Med. 2001;345:715-724.

46. Rydze RT, Bhattarai N, Stapleton JT. GB virus C infection is associated with a reduced rate of reactivation of latent HIV and protection against activation-induced T-cell death. Antivir Ther. 2012;17:1271-1279.

47. Ernst D, Greer M, Akmatova R, et al. Impact of GB virus $C$ viraemia on clinical outcome in HIV-1-infected patients: a 20-year follow-up study. HIV Med. 2014;15:245-250.

48. Sahni H, Kirkwood K, Kyriakides TC, et al. GBV-C viremia and clinical events in advanced HIV infection. J Med Virol. 2014;86:426-432.

49. Xiang J, Wunschmann S, Diekema DJ, et al. Effect of coinfection with GB virus $\mathrm{C}$ on survival among patients with HIV infection. $N$ Engl $J$ Med. 2001;345:707-714.

50. Monath TP. Yellow fever vaccine. In: Plotkin SA, Orenstein WA, Offit PA, eds. Vaccines. 5th ed: Saunders, Philadelphia, PA; 2008:1748.

51. World Health Organization. Vaccines and vaccination against yellow fever. WHO position paper-June 2013. Wky Epidemiol Rec. 2013;88:269-284.

52. Collaborative group for studies on yellow fever vaccines. Duration of post-vaccination immunity against yellow fever in adults. Vaccine. 2014; 32:4977-4984.

53. Ministério da Saúde-Secretaria de Vigilância em Saúde-Departamento de DST, Aids e Hepatites Virais. Brasilia, Brazil. Boletim epidemiológico HIV AIDS. 2014.

54. Klein SL, Marriott I, Fish EN. Sex-based differences in immune function and responses to vaccination. Trans R Soc Trop Med Hyg. 2015;109:9-15.

55 . Cook IF. Sexual dimorphism of humoral immunity with human vaccines. Vaccine. 2008;26:3551-3555.

56. Monath TP, Nichols R, Archambault WT, et al. Comparative safety and immunogenicity of two yellow fever 17D vaccines (ARILVAX and YFVAX) in a phase III multicenter, double-blind clinical trial. Am J Trop Med Hyg. 2002;66:533-541.

57. Pfister M, Kursteiner O, Hilfiker H, et al. Immunogenicity and safety of BERNA-YF compared with two other 17D yellow fever vaccines in a phase 3 clinical trial. Am J Trop Med Hyg. 2005;72:339-346. 